\title{
INHIBITORY EFFECT OF TRICHODERMA ASPERELLUM ISOLATE AGAINST RALSTONIA SOLANACEARUM CAUSING BRINJAL WILT
}

\author{
S. M. N. Islam ${ }^{1 *}$, S. S. Siddique ${ }^{2}$, M. Z. H. Chowdhury ${ }^{1}$ and N. J. Mishu²
}

\begin{abstract}
A native Trichoderma isolate was collected from the agricultural soil of Gazipur. This isolate was identified as a Trichoderma asperellum through morphology and analysis of internal transcribed spacer (ITS) region of ribosomal RNA gene sequence and reconstruction of the phylogenetic tree. The antagonistic effects of the newly identified T. asperellum isolate were assessed against brinjal bacterial wilt caused by Ralstonia solanacearum both in vitro and in planta. Both qualitative and quantitative bioassays were conducted in vitro. For qualitative tests, dual culture and antibacterial activity were carried out, and pathogen growth was observed visually. The antagonism of $T$. asperellum cell free culture filtrate on the growth of $R$. solanacearum was conducted in a quantitative test. Successful antagonism was recorded after both in vitro qualitative tests. In addition, the lowest colony forming unit was recorded in $100 \%$ of CFC $\left(2.4 \pm 0.51 \times 10^{3} \mathrm{cfu} / \mathrm{ml}\right)$ in quantitative test. The T. asperellum inoculated plant showed low disease incidence (13.33\%) when seedlings were challenged with $R$. solanacearum in planta experiment. Disease incidence was $100 \%$ for seedlings when treated with only $R$. solanacearum. The results showed that the isolated and identified $T$. asperellum isolate suppressed $R$. solanacearum growth in vitro and protected the seedling from wilting in planta. Therefore, this isolate could be considered as a potential isolate.
\end{abstract}

Keywords: Internal transcribed spacer (ITS), Trichoderma, Ralstonia, phylogeny, antagonism, bioassay.

\section{Introduction}

Bacterial wilt is caused by a soil-borne, bacterial pathogen Ralstonia solanacearum (Smith) Yabuuchi et al. (formerly Pseudomonas solanacearum). The pathogen is distributed widely in tropical, subtropical, and some temperate region in the world (Yabuuchi et al., 1995). This pathogen limits the production of solanaceous crops such as brinjal, tomato, pepper, tobacco, and potato (Hayward, 1995). For example, yield losses vary from 0 to $91 \%$ in the tomato, 33 to $90 \%$ in the potato, 10 to $30 \%$ in tobacco, 80 to $100 \%$ in the banana, and up to $20 \%$ in the groundnut (Elphinstone, 2005). Walker and Collin (1998) reported more than $\$ 950$ million annual loss from about three million farm families in 80 countries due to bacterial wilt (Walker and Collin, 1998).

\footnotetext{
${ }^{1}$ Institute of Biotechnology and Genetic Engineering, Bangabandhu Sheikh Mujibur Rahman Agricultural University, Gazipur 1706, Bangladesh. ${ }^{2}$ Department of Plant Pathology, Bangabandhu Sheikh Mujibur Rahman Agricultural University, Gazipur 1706, Bangladesh. *Corresponding author: naimul@bsmrau.edu.bd
} 
$R$. solanacearum is difficult to manage due to its ability to grow endophytically, survive in soil, especially in the deeper layers, travel along water, and its relationship with weeds (Cook and Baker, 1983). Disease control is being attempted in different crops with rotation, intercropping, organic manuring, and use of resistant cultivars and chemical control. These control measures are often overcome by the pathogen due to its genetic diversity and wide adaptability (Xue et al., 2009). Moreover, chemical control for wilt disease challenges its limited efficacy, and many of the chemicals have been deregistered worldwide for their detrimental environmental effects (Fujiwara et al., 2011). No specific chemical fungicide has been proved to be $100 \%$ efficient in controlling brinjal bacterial wilt caused by $R$. solanacearum till date. Due to the limited effectiveness of the current chemical control, the use of biological control agents against bacterial wilt has potential in integrated management strategies.

The members of the fungal genus Trichoderma (Ascomycota, Hypocreales) are free living, soil borne microorganism and being used as biological control agents (BCAs) (Mukhopadhyay and Kumar, 2020; Kumar and Khurana, 2021). The species of Trichoderma can colonize plant roots and stimulate plant growth by producing some metabolites (Vinale et al., 2012). Moreover, they suppress plant disease by producing extracellular enzymes like chitinases, glucanases, and proteases (Viterbo et al., 2002). Moreover, it can induce defence responses in plants (Harman et al., 2004). Due to their multiple benefits, many species of Trichoderma have been marketed as biopesticides or biofertilizers (Woo et al., 2014; Kumar et al., 2017). In
Bangladesh, a number of Trichoderma species were well studied for their biological control efficacy against soil borne fungal diseases. For instance, Liton et al. (2019) demonstrated that $T$. harzianum isolates reduced seedling mortality of bush bean caused by Fusarium oxysporum f. sp. phaseoli, Rhizoctonia solani and Sclerotium rolfsii while applied with composts. Another field study showed that Trichoderma enriched compost reduced seedling mortality of chickpea and yield (Talukdar et al., 2017). However, information regarding biocontrol efficacy of Trichoderma species against soil borne bacterial crop diseases is limited. One of the research findings noted that $T$. harzianum was effective against brinjal bacterial wilt, but it was not conclusive (Barua and Bora, 2008). The aim of this study was to isolate and characterize novel strains of Trichoderma from native soils in Bangladesh and its potential in controlling wilt bacterium $R$. solanacearum in brinjal.

\section{Materials and Methods}

\section{Isolation and phylogeny of Trichoderma}

\section{Isolation of Trichoderma isolate}

Soil samples were collected from agricultural fields of Bangabandhu Sheikh Mujiubur Rahman Agricultural University (BSMRAU), Gazipur, Bangladesh during the winter 2019 and brought to the Institute of Biotechnology and Genetic Engineering lab for further research work. Approximately, $300 \mathrm{~g}$ of soil was collected with a soil trowel to a depth of $10-15 \mathrm{~cm}$. Soil samples were kept in individual zip lock bags, labelled, and stored at $4^{\circ} \mathrm{C}$ in a cold room until all samples were analysed.

Soil samples were sieved through a 5-mm 
mesh, and $5 \mathrm{~g}$ of soil was suspended in 50 $\mathrm{mL}$ of sterile $0.1 \%$ Tween 80 , in a $50-\mathrm{mL}$ screw cap plastic tube, and incubated at room temperature for 3 hours. All tubes were inverted five times at 30 minutes intervals. Following incubation, the tubes were kept for sedimentation for 20 seconds. A volume of 100 $\mu \mathrm{L}$ of supernatant from each tube was plated on a Petri plate with Sabouraud dextrose agar (SDA) medium (peptone $10 \mathrm{~g} / \mathrm{L}$, agar $10 \mathrm{~g} / \mathrm{L}$, dextrose $40 \mathrm{~g} / \mathrm{L}$, with $\mathrm{CTAB} 60 \mathrm{mg} / \mathrm{L}$ ) with streptomycin $(30 \mathrm{mg} / \mathrm{L})$ to prevent bacterial contamination. Following inoculation, all plates were incubated at $22^{\circ} \mathrm{C}$ for two weeks. Plates were examined for characteristic dense, compact white mycelium growth every 2-3 days interval. Isolates likely to be Hypocreales were isolated and sub-cultured.

\section{Morphological identification of fungal isolates}

Immediately after sporulation of fungal colonies on SDA, microscopy was conducted to observe their vegetative and reproductive structure. Small plaques from the edge and the centre of each growing colony were transferred onto glass slides, and examined using a compound light microscope.

\section{Sub-culture, DNA isolation, and sequencing} For DNA isolation and sequencing, the fungal isolates were sub-cultured on SDA agar plates without antibiotics. The DNA was extracted by the method described by Islam (2018).

Briefly, a small lump of fungal mycelium of 7-day-old culture was taken into an Eppendorf tube, homogenised using a sterile plastic pestle, resuspended in $1 \mathrm{~mL}$ lysis buffer $(400 \mathrm{mM}$ Tris-HCl, pH 8.0, $60 \mathrm{mM}$ EDTA, $150 \mathrm{mM} \mathrm{NaCl}$, and $1 \% \mathrm{SDS}$ ) and incubated at $50^{\circ} \mathrm{C}$ for 1 hour in a heat block. A volume of $150 \mu 1$ of precipitation buffer (5 $\mathrm{M}$ potassium acetate $60.0 \mathrm{~mL}$, glacial acetic acid $11.5 \mathrm{~mL}$, distilled water $28.5 \mathrm{~mL}$ ) was added and vortexed and incubated on ice for 5 minutes. Following the centrifugation, 500 $\mu \mathrm{l}$ of supernatant was transferred to a new tube, and an equal volume of isopropanol was added to precipitate DNA. The DNA pellet was collected after centrifugation at 18,000 $\mathrm{rcf}$ for 20 minutes and washed with $1 \mathrm{~mL}$ of $70 \%$ ethanol. The DNA pellet was air dried for 10 minutes and dissolved in $100 \mu \mathrm{l}$ of Tris-EDTA (TE) buffer. The quality of the DNA was checked in nano-drop. The Internal transcribed spacer (ITS) region was amplified by polymerase chain reaction (PCR) using ITS1F: CTTGGTCATTTAGAGGAAGTAA and ITS4R: TCCTCCGCTTATTGATATGC (Islam et al., 2018). The thermal profile was as follows: initial denaturation at $90^{\circ} \mathrm{C}$ for 2 min, followed by 35 cycles of denaturation at $95^{\circ} \mathrm{C}$ for $30 \mathrm{sec}$, annealing at $55^{\circ} \mathrm{C}$ for 30 sec, extension at $72^{\circ} \mathrm{C}$ for $1 \mathrm{~min}$, followed by a final extension at $72^{\circ} \mathrm{C}$ for $15 \mathrm{~min}$.

PCR product was electrophoresis in $1 \%$ agarose in $1 \mathrm{x}$ TBE buffer at 120 volts with GelRed nucleic acid stain and visualized under UV light using a 'Molecular Imager ${ }^{\circledR}$ (Gel DocTM). The PCR products were purified using an 'Isolate DNA Kit' (Bioline) following the standard manufacturer protocol. The PCR purified product was sent to First BASE laboratories, Malaysia for both way sequencing.

\section{Phylogenetic tree construction}

Sanger's sequence data from the isolate was manually edited by using Geneious V10. The reference genome sequences were retrieved 
from NCBI. Multiple-alignment was done in Geneious V.11 using MAFT plug-in and the final alignment was manually corrected. The phylogenetic tree was developed by maximum likelihood analysis using RAxML (Stamatakis, 2006) and to search the bestscoring tree under the GTR-GAMMA model with 1000 replicates. The tree was visualised by TreeGraph 2 (Stover and Muller, 2010).

\section{R. solanacearum isolate}

The bacterial isolate was collected from the culture collection of the Department of Plant Pathology, BSMRAU, Bangladesh.

Antagonism of Trichoderma isolate against $R$. solanacearum

\section{Qualitative and Quantitative bioassay}

Qualitative bioassay for antagonism was conducted through the dual culture method and assessing antibacterial activity.

\section{Dual culture bioassay}

Dual culture was conducted according to Khatun et al. (2017). One mycelial disk from the periphery of a 5-day-old TA culture was placed on a PDA plate $3 \mathrm{~cm}$ apart from the $R$. solanacearum inoculation on the same plate. After inoculation, the Petri dish was kept at $25^{\circ} \mathrm{C}$ in the dark for 5 days and was examined after 7 days from each plate. The antagonism activity was recorded on the basis of visual observation only after 7 days of pathogen inoculation.

\section{Metabolite test (Furuya et al., 1997)}

The antibacterial activity of Trichoderma isolate was done by following a method described by Furuya et al. (1997) with some modifications. A small lump of fungal mycelium was placed in the center of Petri dishes containing $20 \mathrm{~mL}$ of SDA medium. The plates were incubated at $28^{\circ} \mathrm{C}$ for one week so that the plate was covered with a mycelial mat. Then the plate was turned upside down. A sheet of filter paper was placed in the Petri dish lid with $0.5 \mathrm{~mL}$ chloroform. The dish was kept at room temperature $\left(25 \pm 2^{\circ} \mathrm{C}\right)$ for $2 \mathrm{~h}$. After complete exclusion of chloroform vapor, the bacterial colonies were overlaid with $5 \mathrm{~mL}$ melted water agar $(1.5 \%)$ at $50^{\circ} \mathrm{C}$ containing a suspension of $R$. solanacearum which was prepared by inoculating into YP broth and kept overnight in agitating condition at $28^{\circ} \mathrm{C}$. The plate thus prepared was incubated at $30^{\circ} \mathrm{C}$ for 2 days. The growth of RA on chloroform-killed fungus was observed at $48 \mathrm{~h}$ of incubation visually.

\section{Quantitative bioassay using in cell-free} culture filtrate

To quantify antagonism of Trichoderma isolate on bacterial growth, cell-free culture filtrate (CFC) of fungus was used. The isolate of Trichoderma was inoculated into $100 \mathrm{~mL}$ of yeast extract broth $(0.1 \%$ yeast extract in distilled water; YEB) and incubated at $25^{\circ} \mathrm{C}$ (Sasan and Bidochka, 2013). Culture filtrate was collected through filtration after 4 days of incubation, using Whatman filter paper no. 44. The culture filtrate was checked for the presence of fungus by plating a sample on SDA. The cell-free culture filtrate was diluted in $0.1 \%$ yeast extract, and $3 \mathrm{~mL}$ of $100 \%, 90 \%, 50 \%$, and $10 \%$ cell-free culture filtrate were inoculated with $300 \mu \mathrm{L}$ of RS $\left(10^{4} \mathrm{cell} / \mathrm{mL}\right)$ in glass tubes. A concentration of $0.1 \%$ yeast extract was used as the control. The glass tubes were kept at $25^{\circ} \mathrm{C}$ in a shaker. The colony forming unit (CFU) per $\mathrm{mL}$ of $R$. solanacearum was estimated on SDA plate by serial dilution method after 48 hours. 


\section{In planta antagonism assay}

Seeds of brinjal variety BARI 10 were collected from Horticulture Research Centre of Bangladesh Agricultural Research Institute (BARI), Joydebpur, Gazipur. All seeds were soaked in sterile distilled water for 30 minutes to enhance germination. Afterward, seeds were immersed in 4\% sodium hypochlorite for 10 minutes and washed with sterile distilled water for three times. Later, seeds were placed on autoclaved sand: soil (1:1) mixture for germination. The spores of $T$. asperellum were collected in water by scraping from 14 days old SDA culture plate and filtered through cheesecloth. A final concentration of spore $1 \times 10^{6}$ per $\mathrm{ml}$ in water was adjusted with a hemocytometer. The bacterial inoculum was prepared by growing in LB broth followed by filtration and centrifugation. The final concentration of RS suspension was made at $1 \times 10^{6}$ per $\mathrm{ml}$ of water with a hemocytometer.

The individual pot containing $300 \mathrm{gm}$ of sterilized soil was inoculated with $10 \mathrm{ml}$ of $T$. asperellum spore suspension (spore suspension, $1 \mathrm{X} 10^{6}$ spore/ml). Following inoculation of fungus, soils in pot were kept for 7 days to develop as soil microbial population. Inoculated soils were occasionally pulverized for uniform the fungal growth. After 10 days of seed germination, the seedlings were transplanted in those $T$. asperellum inoculated pot individually. After 10 days of seedling transplantation (in the $T$. asperellum inoculated pot), all seedlings were inoculated with $10 \mathrm{ml}$ of $R$. solanacearum suspension at the base of the stem.

There were four treatments applied to pot experiment: i) seedlings inoculated with $R$. solanacearum (RS), ii) seedlings inoculated with $T$. asperellum and $R$. solanacearum (TA + RS) iii) seedlings inoculated with $T$. asperellum (TA), and iv) seedlings inoculated with only water. Seedling pot soil inoculated with $R$. solanacearum suspension only was considered as the positive control, whereas seedling pot soil inoculated with water considered as a negative control. There were 15 seedlings per treatment. The number of total wilted seedlings was recorded after 15 days of $R$. solanacearum inoculation. Percentage of wilted seedling counted by using the following formula:

$\%$ Wilt incidence $=\frac{\text { Number of wilted seedling }}{\text { Total number of seedling }} \times 100$

Growth of leaf shoot was observed visually and on photographed accordingly to provide pictorial evidence of this experiment.

\section{Data analysis}

Generalised linear model for the poisson data family was used to analyse the CFU data and mean values were compared by Tukey's post hoc test using 'lsmeans' package. All statistical analyses were performed in ' $\mathrm{R}$ ' $\mathrm{v} 3.3 .1$ ( $\mathrm{R}$ core team, 2016).

\section{Results and Discussion}

\section{Cultural characterization of Trichoderma sp.}

The isolated Trichoderma sp. morphology was similar to the characteristic of the hypocrealean fungus observed on the SDA medium. One isolate viz. isolate $\mathrm{G} 3$ was recorded with white compact mycelium at the initial growth stage. This isolate formed green spores at 14 days of culture on SDA medium with characteristics concentric rings (Fig. 1). The morphology of isolate G3 was similar to T. asperellum T8a observed by Santos-Villalobos et al. (2012). 

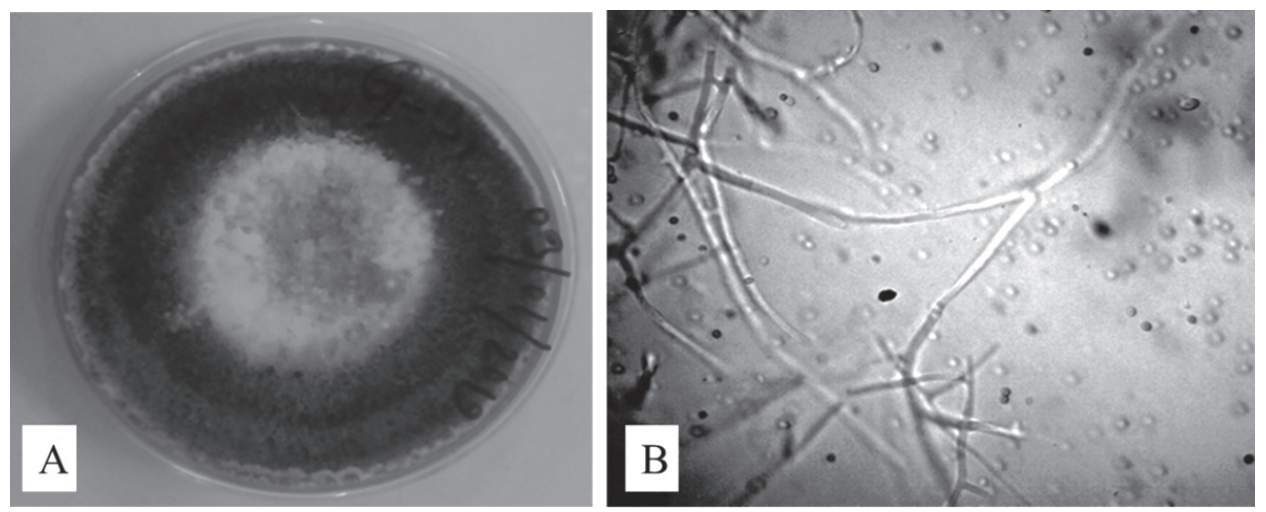

Fig. 1. Trichoderma asperellum isolate G3 culture on SDA medium. A) 14 days old culture plate with green mycelial growth, B) Mycelium and spore under light microscope

However, morphological characteristics are not the key features for Hypocrealean fungus to identify them at the species level (Waalwijk et al.,1996; Islam et al., 2016). Because Hypocrealean fungus often subject to morphological transition due to environmental change/stress and can significantly vary from culture to culture (Seaby, 1996). Therefore, Islam et al. (2016) suggested the importance of molecular analysis to authenticate and to resolve the ambiguities regarding morphological identification.

\section{Phylogeny of Trichoderma sp.}

The ITS sequence data were processed and assembled through Geneious software and submitted to NCBI. The accession number of the isolate is MW052549. The sequence similarity search results showed that the isolate G3 had the closest similarity of $>94 \%$ with $T$. asperellum. A maximum likelihood phylogenetic tree was reconstructed using the ITS sequences of isolate G3 with 46 Trichoderma species and one strain of Hypomyces samuelsii as out group. The phylogenetic analysis showed that the isolate G3 was placed within one Trichoderma clade of 23 species (Fig. 2) and closest to T. asperellum. Molecular identification of Trichoderma species using ITS region is a widely used method (Haque et al., 2020; Feitosa et al., 2019; Rukmana, et al., 2019). Both morphological characteristics and molecular sequence data of fungal strain suggested that the isolate G3 was a $T$. asperellum.

\section{Qualitative and Quantitative bioassay}

Profuse growth and sporulation of $T$. asperellum over $R$. solanacearum colony were observed visually in the dual culture on SDA medium and photographed accordingly (Fig. 3A). The bacterial growth was restricted by $T$. asperellum in duel culture plates. Bacterial growth was completely ceased on chloroform killed T. asperellum treated plates (Fig. 3B). The antagonism $T$. asperellum against $R$. solanacearum, was quantified and estimated on cell free culture filtrate (CFC) method (Fig. 4). The lowest colony forming unit (CFU) of $R$. solanacearum was in $100 \%$ of CFC $\left(2.4 \pm 0.51 \times 10^{3} \mathrm{cfu} / \mathrm{ml}\right)$ and highest 


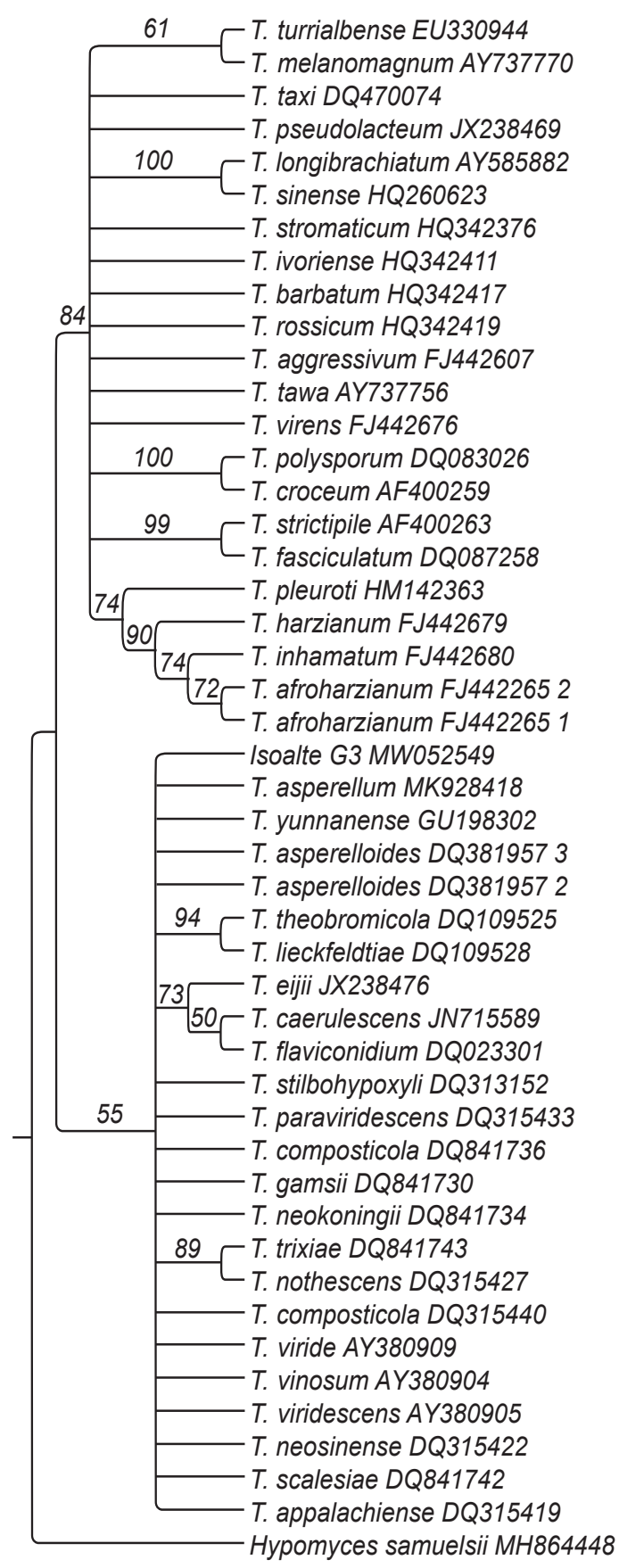

Fig. 2. Maximum likelihood phylogenetic tree of ITS data set with GTR-GAMMA model of 1000 bootstrap replicates. Value on node indicates bootstrap support value.
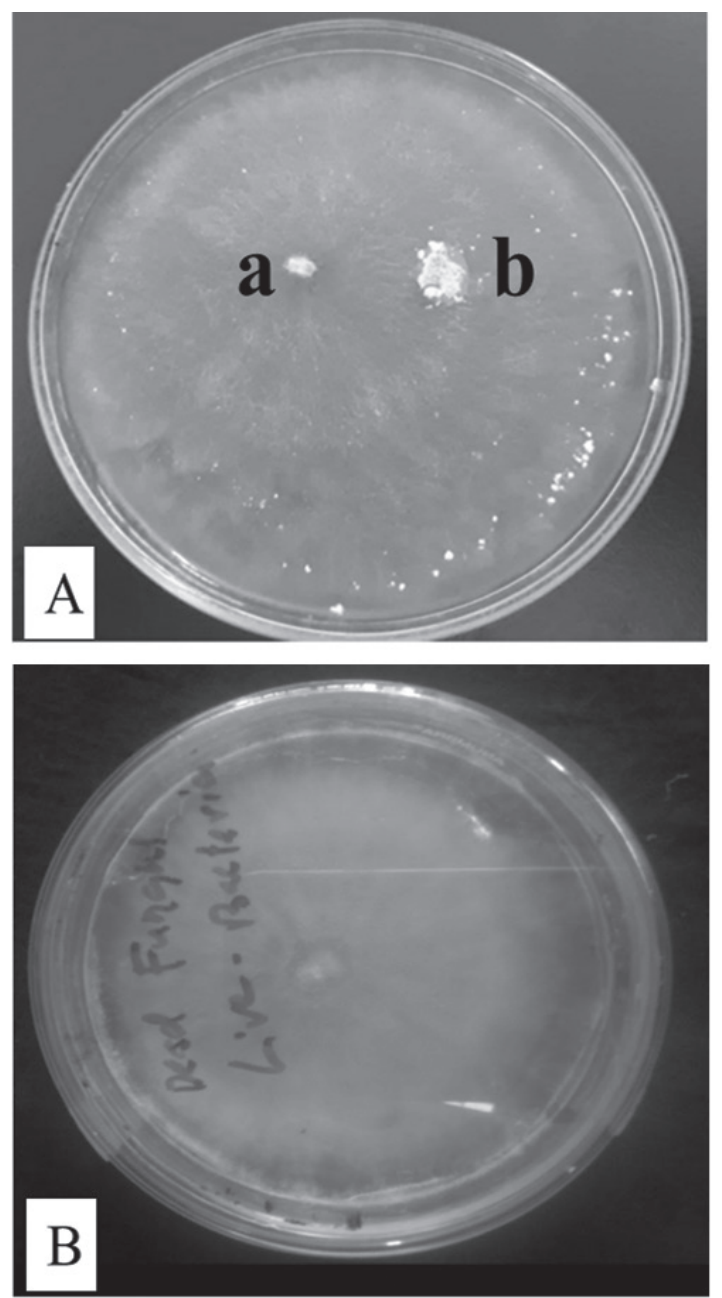

Fig. 3. In vitro qualitative bioassay. A) Dual culture bioassay on SDA medium. The inoculation position of $T$. asperellum sp. Isolate (a), profusing growth of $T$. asperellum over $R$. solanacearum colony (b). B) Metabolite test; growth of $\boldsymbol{R}$. solanacearum on chloroform killed $T$. asperellum. isolate G3.

in $10 \%$ of CFC $\left(1292.4 \pm 24.60 \times 10^{3} \mathrm{cfu} /\right.$ $\mathrm{ml})$. The bacterial growth was significantly reduced in higher concentration $\mathrm{CFC}$ of fungus (Fig. 5).

The present in vitro dual culture study 


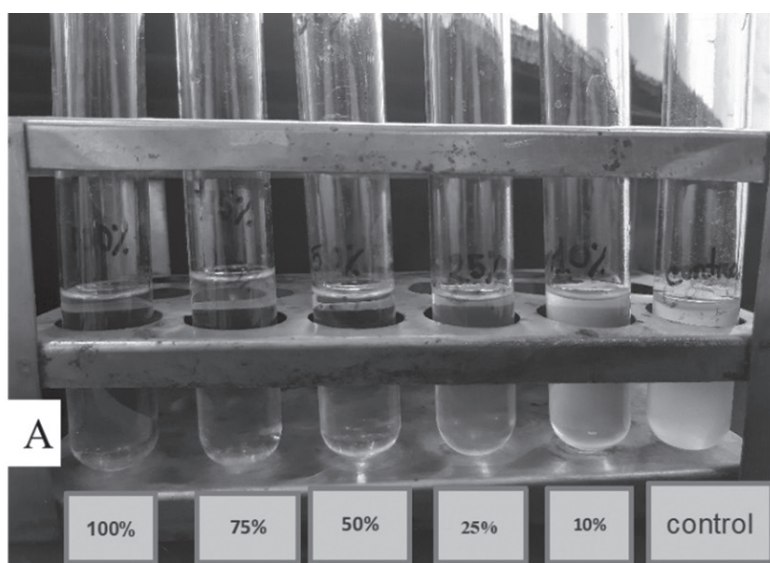

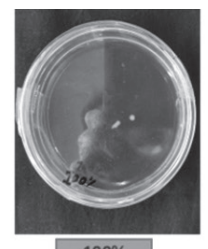

$100 \%$

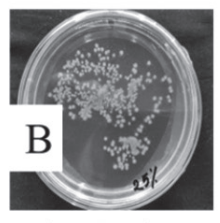

$25 \%$

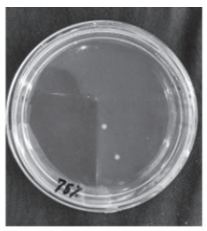

$75 \%$

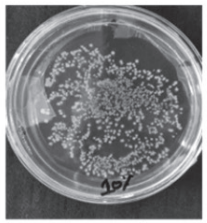

$10 \%$

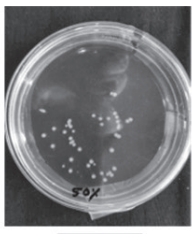

$50 \%$

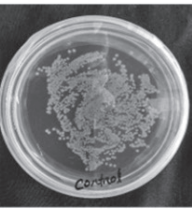

Control

Fig. 4. In vitro quantitative bioassay. A) Growth of $R$. solanacearum in different concentrations CFC of $T$. asperellum isolate G3 and B) CFU of $R$. solanacearum in different concentrations CFC of $T$. asperellum isolate G3, both after $48 \mathrm{hr}$ of incubation.

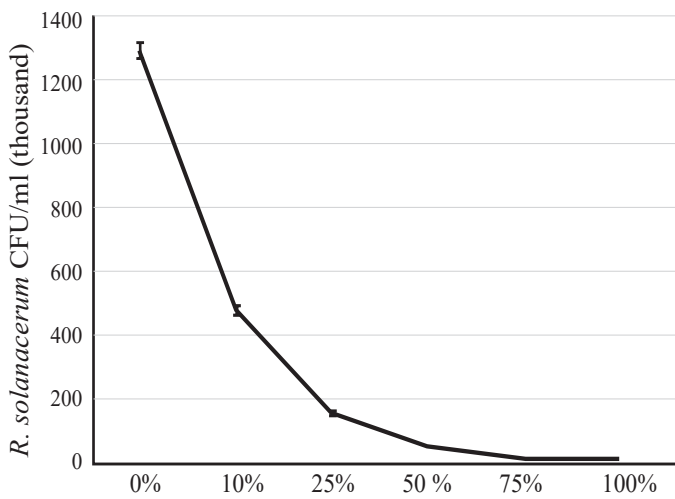

Concentrations of CFC of T. asperellum isolate G3

Fig. 5. Effect of different concentrations of CFC of $T$. asperellum isolate G3 on (CFU ) per $\mathrm{ml}$ of $R$. solanacearum after $48 \mathrm{~h}$ of incubation. (The mean \pm SEM value with lower case alphabet indicate statistical differences on Tukey's post hoc test, $\mathbf{p}<\mathbf{0 . 0 5}$.)

indicated successful antagonistic/inhibitory efficacy of $T$. asperellum isolate G3 against $R$. solanacearum of brinjal. Previous studies have addressed the promising potential of $T$. asperellum as it possesses strong inhibitory effects against various phytopathogens in different crops in vitro. For example, in vitro dual-culture analysis showed effective antagonism of $T$. asperellum against plant pathogenic fungi such as $A$. niger (Haque et al., 2020), Fusarium. oxysporum (f. sp. cucumerinum and f.sp. capsici) (Wu et al., 2017; Islamet al., 2016; Hewedy et al., 2020), F. circinatum, Rhizoctonia solani, and Phomopsis vexans (Islam et al., 2016). Moreover, successful in vitro inhibition was also recorded against some spot and wilt causing bacteria such as Xanthomonas perforans (Chien and Huang, 2020) and $R$. solanacearum (Narasimha Murthy and Srinivas, 2012; Narasimha Murthy et al., 2013).

In Bangladesh, Islam et al. (2016) reported that different strains of $T$. asperellum varied in their in vitro antagonistic effect against plant pathogenic fungi. Alternatively, a single strain of $T$. asperellum was potent against ten strains of $R$. solanacearum in vitro (Narasimha Murthy and Srinivas, 2012; Narasimha Murthy et al., 2013).

Heavy sporulation against the $R$. solanacearum 

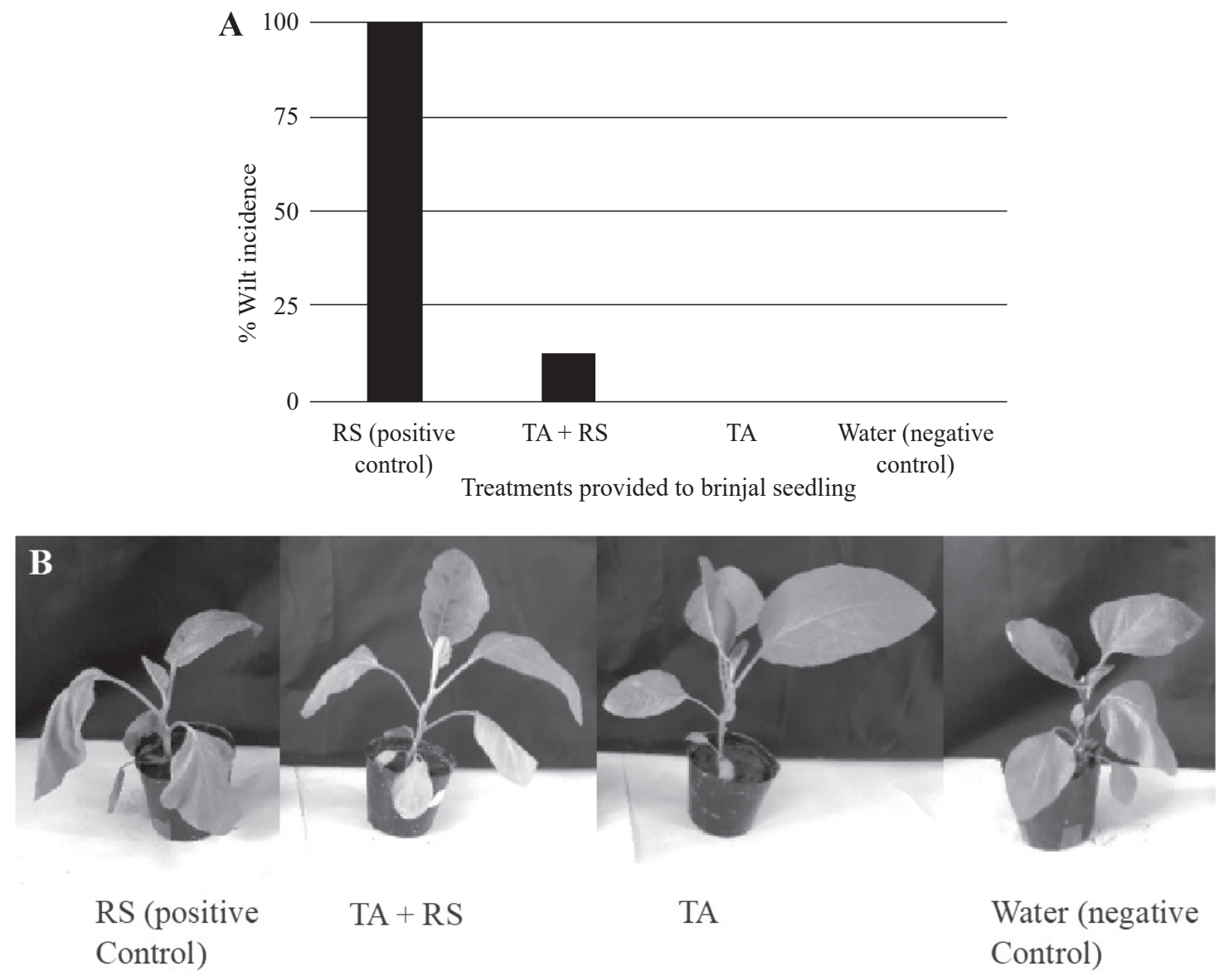

Fig. 6. A) Percent wilt incidence of 15 days after treatments. B) Photographs of brinjal seedlings. (RS: seedlings inoculated with $R$. solanacearum, TA + RS: seedlings inoculated with $T$. asperellum and $R$. solanacearum, TA: seedlings inoculated with $T$. asperellum).

bacterium was recorded in the present dual culture plate during the qualitative antagonistic bioassay. This observation was similar to previous studies (Hermosa et al., 2000; Patel and Saraf, 2017; Kilonzi et al., 2020; Intana et al., 2021), where fast growth and profuse sporulation of Trichoderma were observed against many plant pathogens (2018) recorded mycoparasitism of $T$. asperellum (isolate Ray1715) as it completely overgrew on Phytophthora nicotianae (Phytophthora foot and root rot of citrus). Additionally, the faster growth of $T$. asperellum T76-14 in the dual-culture assay against $F$. incarnatum on PDA suggested a competition mechanism (Intana et al., 2021). According to Jiang et al. (2016) T. asperellum was able to collapse the mycelium of the colonies of the pathogen through dual culture tests by breaking down the pathogenic hyphae into fragments. (Jiang et al., 2016). In antagonism, the sporulation behaviour and aggressiveness of $T$. asperellum were highly 
dependable on type and concentration of target pathogen (Kilonzi et al., 2020; Islam et al., 2016). Therefore, the current study assumed that both competition and parasitism were the mode of action of $T$. asperellum against $R$. solanacearum.

Moreover, the culture filtrate of T. asperellum also inhibited the growth of $R$. solanacearum in vitro. This inhibition efficacy increased with the increase of the initial filtrate concentration of the mentioned antagonist. It was assumed that, this biocontrol agent produced secondary metabolites with effective antibacterial efficacy. Similarly, $\mathrm{Wu}$ et al. (2017) also demonstrated the inhibition rate of filtered fermentation liquor from $T$. asperellum GDFS1009 against $F$. oxysporum f. sp. cucumerinum. Successful inhibition against $F$. oxysporum, $R$. solani, $F$. circinatum and Phomopsis vexans through culture filtrate of Trichoderma strain also reported in Bangladesh (Islam et al., 2016). However, both these studies examined a single culture filtrate concentration. Whereas, the present study indicated that the inhibition efficacy was highly dependent on filtrate concentration. Loc et al. (2020) demonstrated that the chitinases, produced by Trichoderma culture, inhibited the growth of Sclerotium rolfsii, and this inhibition was increased with the increase of chitinases concentration in the media. Previously Zhang et al. (2017) demonstrated the production and antibacterial effect of secondary metabolite by Trichoderma species. However, further research is important to identify the specific metabolites produced by this novel $T$. asperellum responisible for bacterial inhibition.

\section{In planta antagonism assay}

In pot experiment, $13.33 \%$ of seedling mortality was observed in the pot treated with $T$. asperellum $+R$. solanacearum in the in planta, whereas $100 \%$ seedling was observed with wilt symptom after 15 days of R. solanacearum inoculation (Fig. 6).

According to the present investigation, $T$. asperellum completely ceased wilt development by $R$. solanacearum in brinjal seedling. This result was supported by Kipngeno et al., (2015), who recorded significantly lower $(24.07 \%)$ postemergence seedling damping-off by Pythium aphanidermatum in tomatoes compared to control (65.89\%). Similarly, Gurung (2018) revealed high efficacy (reduction of infection by $95-100 \%$ ) of $T$. asperellum in preventing $P$. nicotianae infections in citrus seedlings in the greenhouse, but did not found any significant effect on the height of seedlings as compared to untreated control. A number of previous studies also reported the bactericidal efficacy of $T$. asperellum. Inoculation of $T$. asperellum Tc-Jjr-02 at six hours before and after and simultaneously with pathogens provided protection (reducing the symptom index by $56-63 \%$ ) for young tobacco plants against tobacco bacterial wilt disease caused by $R$. solanacearum (Jalaluddin et al., 2021). Previous studies (Konappa et al., 2020, Konappa et al., 2018, Mohamed et al., 2020) also revealed a reduction of potato and tomato wilt, caused by Ralstonia solanacearum (Smith) by $T$. asperellum isolate under greenhouse and field conditions. Even leaf spray of $T$. asperellum also reduced the growth of bacterial spots on tomato caused by Xanthomonas (Chien and Huang, 2020). In addition to disease reduction, T. asperellum also enhanced tomato seed germination, fruit 
yield, plant growth and increased the dry weight of plant biomass promotion under field conditions (Konappa et al., 2020, Jalaluddin et al., 2021).

The importance of bacterial wilt in brinjal production was mentioned earlier by different authors (Faruk, 2019, Rahman, 2010, Nahar, 2019). It may be mentioned that this is the first research showing suppression of bacterial wilt of brinjal in Bangladesh. It is always difficult to extrapolate the biocontrol activity of a given strain from the laboratory to natural environments (Hermosa et al., 2000). As this strain demonstrated potential in controlling the bacterial wilt of brinjal both in vitro and in planta, further field experiments should be conducted to confirm the efficacy in detail.

\section{Acknowledgments}

The authors acknowledged the Research Management Wing (RMW), Bangabandhu Sheikh Mujibur Rahman Agricultural University, Bangladesh for providing research fund.

\section{References}

Barua, L. and B. C. Bora. 2008. Comparative efficacy of Trichoderma harzianum and Pseudomonas fluorescens against Meloidogyne incognita and Ralstonia solanacearum complex in brinjal. Indian J. Nematol. 38(1): 86-89.

Chien, Y. C. and C. H. Huang. 2020. Biocontrol of bacterial spot on tomato by foliar spray and growth medium application of Bacillus amyloliquefaciens and Trichoderma asperellum. European J. Plant Path. 156: 995-1003.

Cook, R. J. and K. F. Baker. 1983. The nature and practice of biological control of plant pathogens. American Phytopathological Society.

Elphinstone, J. G. 2005. The current bacterial wilt situation: a global overview. Bacterial wilt disease and the Ralstonia solanacearum species complex. Pp. 9-28. American Phytopathological Society Press; St Paul, MN.

Faruk, M., M. Islam, F. Khatun, M. Hossain and T. Dey. 2019. Integrated management of bacterial wilt and root knot nematode of brinjal." Bangladesh J. Agril. Res. 44(3): 427-437.

Feitosa, Y. B., V. Cruz-Magalhães, R. C. ArgoloFilho, J. T. de Souza and L. L. Loguercio. 2019. Characterization of genetic diversity on tropical Trichoderma germplasm by sequencing of rRNA internal transcribed spacers. BMC Res. Notes. 12(1): 1-6.

Fujiwara, A., M. Fujisawa, R. Hamasaki, T. Kawasaki, M. Fujie and T. Yamada. 2011. Biocontrol of Ralstonia solanacearum by treatment with lytic bacteriophages. Appl. Environ. Microbiol. 77(12): 4155-4162.

Furuya, N., S. Yamasaki, M. Nishioka, I. Shiraishi, K. Iiyama and N. Matsuyama. 1997. Japanese J. Phytopathol. 63(6): 417-424.

Gurung, M. 2018. Evaluation of Trichoderma asperellum as Biocontrol Agent for Phytophthora Foot and Root Rot of Citrus, Texas A \& M University-Kingsville.

Haque, Z., M. S. Iqbal, A. Ahmad, M. S. Khan and J. Prakash. 2020. Molecular characterization of Trichoderma spp. isolates by internal transcribed spacer (ITS) region sequencing technique and its use as a biocontrol agent. Open Biotech. J. 14(1): 70-77.

Harman, G. E., C. R. Howell, A. Viterbo, I. Chet and M. Lorito. 2004. Trichoderma species-opportunistic, avirulent plant 
symbionts. Nat. Rev. Microbiol. 2: 43-56. doi: $10.1038 /$ nrmicro797

Hayward, A. C. 1995. Pseudomonas solanacearum. In Singh, U.S., Singh, R.P. and Kohmoto, K. (ed.), Pathogenesis and Host Specificity in Plant Disease: Histopathol. Biochem. Genet. Molecul. Bas. 1: 139-215.

Hewedy, O. A., K. S. Abdel-Lateif and R. A. Bakr. 2020. Genetic diversity and biocontrol efficacy of indigenous Trichoderma isolates against Fusarium wilt of pepper. $J$. Basic Microbiol. 60(2): 126-135.

Hermosa, M. R., I. Grondona, E. T. Iturriaga, J. M. Diaz-Minguez, C. Castro, E. Monte and I. Garcia-Acha. 2000. Molecular characterization and identification of biocontrol isolates of Trichoderma spp. Appl. Environ. Microbiol. 66(5): 1890-1898.

Intana, W., S. Kheawleng and A. Sunpapao. 2021. Trichoderma asperellum T76-14 released volatile organic compounds against postharvest fruit rot in muskmelons (Cucumis melo) caused by Fusarium incarnatum. J. Fungi. 7(1): 46.

Islam, S. M. N. 2018. Systematics, ecology and plant associations of Australian species of the genus Metarhizium (Doctoral Dissertation, Queensland University of Technology).

Islam, M. M., D. M. Hossain, M. M. E. Rahman, K. Suzuki, T. Narisawa, I. Hossain and N. Harada. 2016. Native Trichoderma strains isolated from Bangladesh with broad spectrum antifungal action against fungal phytopathogens. Arch. Phytopathol. Plant Protec. 49(1-4): 75-93.

Jalaluddin, A. K., A. S. Li'aini and A. E. Prihatiningrum. 2021. Characterizations of Trichoderma sp. and its effect on Ralstonia solanacearum of tobacco seedlings. J. Hama dan Penyakit Tumbuhan Tropika. 21(1): 8-19.

Jiang, H., L. Zhang, J. Z. Zhang, M. R. Ojaghian and K. D. Hyde. 2016. Antagonistic interaction between Trichoderma asperellum and Phytophthora capsici in vitro. J. Zhejiang Univ. Sci. 17(4): 271-281.

Khatun, A., T. Farhana, A. A. Sabir, S. M. N. Islam, H. M. West, M. Rahman and T. Islam. 2017. Pseudomonas and Burkholderia inhibit growth and asexual development of Phytophthora capsici. Z Naturforsch C. 23: 123-135.

Kilonzi, J. M., J. J. Mafurah and M. W. Nyongesa. 2020. In vitro efficacy of Trichoderma asperellum and detached leaflet assay on late blight pathogen: Phytophthora infestans. African J. Microbiol. Res. 14(5): 148-157.

Kipngeno, P., T. Losenge, N. Maina, E. Kahangi and P. Juma. 2015. Efficacy of Bacillus subtilis and Trichoderma asperellum against Pythium aphanidermatum in tomatoes. Biol. Control. 90: 92-95.

Konappa, N., S. Krishnamurthy, C. N. Siddaiah, N. S. Ramachandrappa and S. Chowdappa. 2018. Evaluation of biological efficacy of Trichoderma asperellum against tomato bacterial wilt caused by Ralstonia solanacearum. Egyptian J. Biol. Pest Control. 28(1): 1-11.

Konappa, N., S. Krishnamurthy, U. C. Arakere, S. Chowdappa and N. S. Ramachandrappa. 2020. Efficacy of indigenous plant growthpromoting rhizobacteria and Trichoderma strains in eliciting resistance against bacterial wilt in a tomato. Egyptian $J$. Biol. Pest Control. 30(1): 1-13.

Kumar, N. and S. M. P. Khurana. 2021. Trichoderma-plant-pathogen interactions for benefit of agriculture and environment. 
Pp. 41-63. In: Jogaiah S, (ed.) Biocontrol Agents and Secondary Metabolites. Woodhead Publishing.

Kumar, G., A. Maharshi, J. Patel, A. Mukherjee, H. Singh and B. Sarma. 2017. Trichoderma : A Potential Fungal Antagonist to Control Plant Diseases. SATSA Mukhapatra Annual Techn. 11: 206-218.

Liton, M. J. A., M. K. A. Bhuiyan, R. Jannat, J. U. Ahmed, M. T. Rahman and M. T. Rubayet. 2019. Efficacy of Trichoderma-fortified compost in controlling soil-borne diseases of bush bean (Phaseolus vulgaris L.) and sustainable crop production. Advan. Agric. Sci.7(2): 123-136.

Loc, N. H., N. D. Huy, H. T. Quang, T. T. Lan and T. T. Thu-Ha. 2020. Characterisation and antifungal activity of extracellular chitinase from a biocontrol fungus, Trichoderma asperellum PQ34. Mycology. 11(1): 38-48.

Mohamed, B. F., N. M. Sallam, S. A. Alamri, K. A. Abo-Elyousr, Y. S. Mostafa and M. Hashem. 2020. Approving the biocontrol method of potato wilt caused by Ralstonia solanacearum (Smith) using Enterobacter cloacae PS14 and Trichoderma asperellum T34. Egyptian J. Biol. Pest Control. 30: 1-13.

Mukhopadhyay, R and D. Kumar. 2020. Trichoderma: a beneficial antifungal agent and insights into its mechanism of biocontrol potential. Egyptian J. Biol. Pest Control. 30 (1): 1-8.

Nahar, N., M. R. Islam, M. M. Uddin, P. de Jong, P. C. Struik and T. J. Stomph. 2019. Disease management in eggplant (Solanum melongena $\mathrm{L}$.) nurseries also reduces wilt and fruit rot in subsequent plantings: A participatory testing in Bangladesh. Crop Protec. 120: 113-124.

Narasimha Murthy, K., D. Nirmala Devi and C. Srinivas. 2013. Efficacy of Trichoderma asperellum against Ralstonia solanacearum under greenhouse conditions. Annals of Plant Sci. 2: 342-350.

Narasimha Murthy, K. and C. Srinivas. 2012. In vitro screening of bioantagonistic agents and plant extracts to control bacterial wilt (Ralstonia solanacearum) of tomato (Lycopersicon esculentum). J. Agric. Tech. 8(3): 999-1015.

Patel, S. and M. Saraf. 2017. Biocontrol efficacy of Trichoderma asperellum MSST against tomato wilting by Fusarium oxysporum $\mathrm{f}$. sp. lycopersici. Arch. Phytopathol. Plant Protec. 50(5-6): 228-238.

R Core Team. 2016. R: A Language and Environment for Statistical Computing. Vienna, Austria: $\mathrm{R}$ Foundation for Statistical Computing. https://www.Rproject.org/.

Rahman, M. F., M. R. Islam, T. Rahman and M. B. Meah. 2010. Biochemical characterization of Ralstonia solanacerum causing bacterial wilt of brinjal in Bangladesh Progress. Agri. 21(1-2): 9-19.

Rukmana, S., A. N. Ansori, M. K. Kusala, U. Utami, D. Wahyudi and A. A. Mandasari. 2020. Molecular Identification of Trichoderma Isolates from Sugarcane Bagasse Based on Internal Transcribed Spacer (ITS) rDNA. Res. J. Pharmacy Tech. 13(7): 3300-3304.

Santos-Villalobos, S., L. E. HernándezRodríguez, F. Villaseñor-Ortega and J. J. Peña-Cabriales. 2012. Production of Trichoderma asperellum T8a spores by a "home-made" solid-state fermentation of mango industrial wastes. BioResources. 7(4): 4938-4951.

Sasan, R. K. and M. J. Bidochka. 2013. Antagonism of the endophytic insect pathogenic fungus Metarhizium robertsii against the bean plant pathogen Fusarium solani f. sp. phaseoli. Canadian J. Plant Path. 35(3): 288-293. 
Seaby, D. 1996. Differentiation of Trichoderma taxa associated with mushroom production. Plant Path. 45: 905-912.

Stamatakis, A. 2006. RAxML-VI-HPC: maximum likelihood-based phylogenetic analyses with thousands of taxa and mixed models. Bioinformat. 22: 2688-2690.

Stover, B. C and K. F. Muller. 2010. Tree Graph 2: Combining and visualizing evidence from different phylogenetic analyses. BMC Bioinformat. 11: 7.

Talukdar, P., M. M. Siddiqa, M. M. I. Masum, A. B. M. Habibullah and M. K. A. Bhuiyan. 2017. Effect of Trichoderma fortified compost on disease suppression, growth and yield of chickpea. Int. J. Env. Agril. Biotech. 2(2): 238736.

Vinale, F., K. Sivasithamparam, E. L. Ghisalberti, M. Ruocco, S. Woo and M. Lorito. 2012. Trichoderma secondary metabolites that affect plant metabolism. Nat. Product Comm. 7(11): 1934578X1200701133.

Viterbo, A., O. Ramot, L. Chernin and I. Chet. 2002. Significance of lytic enzymes from Trichoderma spp. in the biocontrol of fungal plant pathogens. Antonie Van Leeuwenhoek. 81(1): 549-556.

Waalwijk, C., J. R. Koning, R. Baayen and W.
Gams. 1996. Discordant groupings of Fusarium spp. from sections Elegans, Liseola and Dlaminia based on ribosomal ITS1 and ITS2 sequences. Mycologia. 88: 361-368.

Walker, T., and N. H. Collin. 1998. Priority setting at CIP for the 1998-2000 Medium Term Plan. International Potato Centre, Lima, Peru.

Woo, S., M. Ruocco and F. Vinale et al. 2014. Trichoderma-based Products and their Widespread Use in Agriculture. The Open Mycol. J. 8, (Suppl-1, M4): 71-126.

Wu, Q., R. Sun, M. Ni, J. Yu, Y. Li, C. Yu and J. Chen. 2017. Identification of a novel fungus, Trichoderma asperellum GDFS1009, and comprehensive evaluation of its biocontrol efficacy. PloS one. 12(6): e0179957.

Xue, Q. Y., Yu. Chen, S. M. Li, L. F. Chen, G. C. Ding, D. W Guo and J. H. Guo. 2009. Evaluation of the strains of Acinetobacter and Enterobacter as potential biocontrol agents against Ralstonia wilt of tomato. Biol. Control. 48(3): 252-258.

Yabuuchi, E., Y. Kosako, I. Yano, H. Hotta and Y. Nishiuchi. 1995. Transfer of 